\title{
Is colonic propionate delivery a novel solution to improve metabolism and inflammation in overweight or obese subjects?
}

\author{
Patrice D Cani ${ }^{1,2}$
}

Increased intake of dietary fibre has been linked to beneficial impacts on health for decades. Strikingly, the exact mechanisms of action are not yet fully understood. Among the different families of fibres, prebiotics have gained attention mainly because of their capacity to selectively modulate the gut microbiota composition and promote health benefits. ${ }^{1}$ Prebiotics are fermented by gut bacteria into shortchain fatty acids (SCFA) such as acetate, butyrate and propionate, but multiple other metabolites have also been described. ${ }^{2}$ SCFAs have been connected with different physiological processes including the regulation of glucose and lipid metabolism but also energy, immunity and inflammation. Therefore, the gut microbiota has been suggested as a potential target to mitigate cardiometabolic disorders associated with obesity (for review, see ref 3).

Among the different SCFAs, propionate has attracted the most attention because of its capacity to bind to specific receptors and trigger the secretion of gut peptides such as glucagon-like peptide-1 and peptide YY which are involved in the regulation of appetite and glucose metabolism. ${ }^{3}$ In addition, propionate has been found to enhance the development of regulatory $\mathrm{T}$ cells and to reduce the expansion of proinflammatory Th17 cells. ${ }^{4}$ Therefore, increasing the endogenous production of propionate or its delivery in the colon is an attractive solution to improve metabolic disorders.

Pioneering work by Chambers and colleagues has shown that inulin-propionate ester (IPE) can target the delivery of propionate to the colon and ameliorate body weight gain, glycaemia and the accumulation of abdominal fat. ${ }^{5}$ However, one of the major caveats in this seminal study

${ }^{1}$ Louvain Drug Research Institute, Université catholique de Louvain (UCLouvain), Brussels, Belgium

${ }^{2}$ Walloon Excellence in Life Sciences and BIOtechnology (WELBIO), Brussels, Belgium

Correspondence to Professor Patrice D Cani, Louvain Drug Research Institute, Universite catholique de Louvain (UCLouvain), Brussels 1200, Belgium; patrice.cani@uclouvain.be was the lack of evidence that the observed effects were due to the presence of inulin itself on IPE or the delivery of propionate into the colon.

In GUT, Chambers and colleagues addressed this gap of knowledge and expanded on their previous findings. ${ }^{6}$ For 42 days, they investigated the impact of dietary supplementation with either $20 \mathrm{~g} /$ day IPE versus inulin as a positive control and used a low-fermentable fibre cellulose as a negative control. In this randomised cross-over trial performed in adults with overweight and obesity, the authors found that both IPE and inulin similarly improved insulin sensitivity compared with the low-fermentable fibre control cellulose. This observation is of great importance and strongly suggests that inulin fermentation per se is sufficient to improve glucose homeostasis without the requirement of targeted propionate delivery in the colon using IPE. Another interesting finding is that the apparent improvement in glucose metabolism was independent of any significant differences in body weight, food intake or GI side effects compared with the low-fermentable fibre cellulose. This finding also strongly suggests that the fermentation of fibres (ie, inulin or IPE) and their metabolites can contribute to the beneficial effects observed on glucose metabolism.

However, despite showing a similar impact on metabolism, inulin and IPE differentially affected the gut microbiota composition and immune parameters. Indeed, in their study, Chambers et al discovered that IPE supplementation was accompanied by a reduction in circulating interleukin (IL)-8, a proinflammatory chemokine. By using in vitro analysis, they demonstrated the proof of concept that propionate can directly reduce the secretion of IL- 8 by peripheral blood mononuclear cells isolated from healthy humans. Although this set of data is interesting, it is difficult to ascertain whether a similar propionate-dependent mechanism also occurs in vivo in humans. The authors also found a small but significant increase in IgG levels in IPE-treated subjects versus those receiving cellulose supplementation. This interesting discovery is the first evidence in humans that promoting the delivery of propionate in the colon may affect adaptive immunity. It is worth noting that previous preclinical and clinical data have shown that supplementation with inulin-type fructans was associated with a lower inflammatory tone and a reinforcement of the gut barrier. ${ }^{78}$ Nevertheless, it remains unknown if these effects are directly linked with the production of propionate, changes in the proportion of the overall levels of SCFAs, or the presence of any other bacterial metabolites.

Alongside the changes in the levels of SCFAs, plasma metabolome analysis revealed that each of the supplementation periods was correlated with different profiles and that specific metabolites were positively or negatively associated with fasting insulin according to the dietary treatment (eg, tyrosine, glutamine, $N$-acetyl glycoproteins). However, whether these metabolites are causally linked with the regulation of glucose homeostasis remains to be demonstrated. Interestingly, Koh et al recently described a precise mechanism by which a specific microbial metabolite called imidazole propionate, which is derived from an amino acid (ie, histidine) other than those observed in the present study, could contribute to the onset of insulin resistance. ${ }^{9}$ Indeed, the authors found that imidazole propionate directly contributes to the development of insulin resistance and diabetes by blocking the insulin receptor signalling pathway. ${ }^{9}$ Of note, this metabolite was apparently not affected in the study by Chambers and colleagues.

In conclusion, beyond the interesting finding that IPE was not superior to classical inulin fibre for the improvement of insulin sensitivity, there were specific effects on both the gut microbiota composition and immune factor modulation. This is an attractive finding, although none of the data or any of the correlations with metabolites or bacteria indicated any specific novel mechanistic insights. Nevertheless, this very interesting paper is one of the first in the field to appropriately compare the impact of two fermentable fibres (ie, inulin or IPE) versus a less fermentable fibre (cellulose). In addition, as discussed earlier in this commentary, the researchers provide a range of data and clearly show that targeting the microbiota by using prebiotics offers the ability to induce many metabolic improvements, including changes at the level of immunity. However, evidence that metabolites 
and a bacterial IPE signature are linked with the observed metabolic and immune effects remains lacking.

Contributors PDC has written the commentary.

Funding PDC is a senior research associate at FRSFNRS (Fonds de la Recherche Scientifique), recipient of grants from FNRS (FRFS-WELBIO-WELBIO-CR2017C-02), The Excellence Of Science (EOS-30770923) and the Funds Baillet Latour (Grant for Medical Research 2015), SPW-DGO6 (NUTRIMICROBIOTA C-7906).

Competing interests $\mathrm{PDC}$ is an inventor on patent applications dealing with the use of $A$. muciniphila and its components for the treatment of obesity and related disorders. PDC is a co-founder of A-Mansia Biotech.

Patient consent for publication Not required.

Provenance and peer review Commissioned; internally peer reviewed.

\section{(6)}

\section{OPEN ACCESS}

Open access This is an open access article distributed in accordance with the Creative Commons Attribution Non Commercial (CC BY-NC 4.0) license, which permits others to distribute, remix, adapt, build upon this work non-commercially, and license their derivative works on different terms, provided the original work is properly cited, appropriate credit is given, any changes made indicated, and the use is non-commercial. See: http:// creativecommons.org/licenses/by-nc/4.0/.

(c) Author(s) (or their employer(s)) 2019. Re-use permitted under CC BY-NC. No commercial re-use. See rights and permissions. Published by BMJ.

(D) Check for updates

To cite Cani PD. Gut 2019;68:1352-1353.

Received 25 March 2019

Revised 15 April 2019

Accepted 17 April 2019

Published Online First 26 April 2019

\section{SLinked}

- http://dx.doi.org/10.1136/gutjnl-2019-318424

Gut 2019;68:1352-1353

doi:10.1136/gutjnl-2019-318776

\section{REFERENCES}

1 Gibson GR, Hutkins R, Sanders ME, et al. Expert consensus document: the International Scientific Association for Probiotics and Prebiotics (ISAPP) consensus statement on the definition and scope of prebiotics. Nat Rev Gastroenterol Hepatol 2017;14:491-502.
2 Louis P, Flint HJ. Formation of propionate and butyrate by the human colonic microbiota. Environ Microbiol 2017;19:29-41.

3 Cani PD, Van Hul M, Lefort C, et al. Microbial regulation of organismal energy homeostasis. Nat Metab 2019;1:34-46

4 Arpaia N, Campbell C, Fan X, et al. Metabolites produced by commensal bacteria promote peripheral regulatory T-cell generation. Nature 2013;504:451-5.

5 Chambers ES, Viardot A, Psichas A, et al. Effects of targeted delivery of propionate to the human colon on appetite regulation, body weight maintenance and adiposity in overweight adults. Gut 2015;64:1744-54

6 Chambers ES, Byrne CS, Morrison DJ, et al. Dietary supplementation with inulin-propionate ester or inulin improves insulin sensitivity in adults with overweight and obesity with distinct effects on the gut microbiota, plasma metabolome and systemic inflammatory responses: a randomised cross-over trial. Gut 2019;68:1430-8.

7 Cani PD, Possemiers S, Van de Wiele T, et al. Changes in gut microbiota control inflammation in obese mice through a mechanism involving GLP-2-driven improvement of gut permeability. Gut 2009:58:1091-103.

8 Dewulf EM, Cani PD, Claus SP, et al. Insight into the prebiotic concept: lessons from an exploratory, double blind intervention study with inulin-type fructans in obese women. Gut 2013:62:1112-21.

9 Koh A, Molinaro A, Ståhlman M, et al. Microbially produced imidazole propionate impairs insulin signaling through mTORC1. Cell 2018;175:947-61. 